\title{
The predictive value of preoperative positive urine cytology for development of bladder cancer after nephroureterectomy in patients with upper urinary tract urothelial carcinoma: A retrospective multi-center case- control study and meta-analysis
}

Bo Fan ( $\sim$ fanbo@dmu.edu.cn )

Department of Urology, Second Affiliated Hospital of Dalian Medical University, Dalian, Liaoning Province

\section{Yuanbin Huang}

Department of Clinical Medicine, Second Affiliated Hospital of Dalian Medical University, Dalian, Liaoning Province

\section{Shuang Wen}

Department of Pathology, Dalian Friendship Hospital, Dalian, Liaoning Province

\section{Min Sun}

Department of General Surgery, Taihe Hospital, Hubei University of Medicine, Shiyan, Hubei Province

\section{Xinrui Yang}

Department of Clinical Medicine, Second Affiliated Hospital of Dalian Medical University, Dalian, Liaoning Province

Man Sun

Department of Clinical Medicine, Dalian Medical University, Dalian, Liaoning Province

\section{Yuting Chen}

Department of Clinical Medicine, Dalian Medical University, Dalian, Liaoning Province

\section{Yan Huang}

Department of Urology, Cancer Hospital of China Medical University, Liaoning Cancer Hospital and Institute, Shenyang, Liaoning Province

\section{Yumei Wang}

Department of Clinical Laboratory, Second Affiliated Hospital of Dalian Medical University, Dalian, Liaoning Province

\section{Research}

Keywords: Upper urinary tract urothelial carcinoma, Urine cytology, Intravesical recurrence, Case- control study, Metaanalysis

Posted Date: August 2nd, 2020

DOI: https://doi.org/10.21203/rs.3.rs-49011/v1

License: (c) (i) This work is licensed under a Creative Commons Attribution 4.0 International License. Read Full License 


\section{Abstract}

Background: Upper urinary tract urothelial carcinoma (UUT-UC) is a rare and severe urinary malignancy. Urine cytology is a common clinical method for the early diagnosis of urologic neoplasms. Several studies have explored the relationship between preoperative urine cytology and intravesical recurrence in patients with UUT-UC. However, the results of these studies are controversial or even contradictory, and investigations with UUT-UC patients in Northeast China are rare.

Methods: In this retrospective case-control study, we first estimated the prognostic significance of preoperative urine cytology in the outcomes of intravesical recurrence in 142 patients with UUT-UC after radical nephroureterectomy (RNU). A nomogram model was established and we evaluated its effectiveness. Subsequently, after searching several databases, including PubMed, Embase, and Ovid, we quantitatively combined our results with the published data in a meta-analysis.

Results: Our case-control study demonstrated that patients with muscle-invasive tumors (T2-T4) were more prone to preoperative positive urine cytology than those with non-muscle-invasive tumors (Tis-T1), suggesting that preoperative positive urine cytology may be associated with the aggressive form of UUT-UC. Kaplan-Meier curves demonstrated that the patients with positive urine cytology had significantly poorer intravesical recurrence-free survival (IV-RFS). Additionally, preoperative urine cytology (hazard ratio, $\mathrm{HR}=3.24$ ) and lymph node status $(\mathrm{HR}=2.67)$ were validated as significant independent predictors of intravesical recurrence by multivariate analysis. Nomogram, calibration plots, AUC values and the C-index demonstrated that the predictive accuracy was significantly improved when preoperative urine cytology was combined. Subsequently, adding to our study, 11 eligible articles from 2010 to 2016 containing 2942 patients were sifted out for our meta-analysis. Overall analysis showed that preoperative positive urine cytology was associated with a $56 \%$ increased risk of intravesical recurrence $(H R=1.56)$. In the subgroup analysis by region, study type, and sample size, the pooled HR was statistically significant for the Japan subgroup ( $H R=1.45)$, China subgroup ( $H R=1.66)$, cohort study subgroup ( $H R=1.44)$, and case-control study subgroup $(H R=1.77)$, the subgroup with sample size greater than or equal to $100(H R=1.42)$, and the subgroup with sample size less than $100(\mathrm{HR}=2.95)$.

Conclusions: Preoperative urine cytology significantly correlated with intravesical recurrence in patients with UUT-UC after RNU, although these results need to be interpreted with caution. Large, prospective trials are required to further confirm its prognostic significance.

\section{Introduction}

Upper urinary tract urothelial carcinoma (UUT-UC), which is widely acknowledged to be a urinary malignancy that originates from the urothelium, which runs from the renal pelvis and calyces to the distal ureter, is usually considered an infrequent urothelial tumor, accounting for $5-10 \%$ of urothelial carcinomas. Statistically, the average prevalence is 1-2 per 100,000 in the United States[1, 2].UUT-UC is more commonly diagnosed in Asian countries, such as China (including mainland and Taiwan), and can even reach 20-30 cases per 100 persons in high-incidence areas[3, 4]. Although the industry-recognized standard treatment for UUT-UC is radical nephroureterectomy (RNU) with bladder cuff excision, several authors have investigated whether subsequent bladder cancer occurrence is highly common after the management of UUT-UC. During follow-up, approximately $22-50 \%$ of UUT-UC patients who undergo RNU have bladder cancer recurrence; additionally, the recurrence rates at 5 years can reach more than 30\%[5-

8]. Recurrence and rapid progression of bladder cancer after UUT-UC greatly increase the psychological anxiety and economic burden of patients and even lower their quality of life[9]. 
Previously, there were controversial predictive factors that resulted in poor prognosis for UUT-UC and intravesical recurrence, such as patient-specific factors (age, sex, diabetes mellitus or history of bladder cancer), tumor-related factors (location, size, $T$ stage or architecture) and environmental factors (smoking, long-term use of aristolochic acid, etc.)[9-13]. It is worth noting that the 2-year recurrence-free survival rate is less than $56 \%$ for stage $\geq \mathrm{pT} 1$ cancer, and the 5-year specific survival rate is less than $50 \%$ for stage $\geq \mathrm{pT} 2[14$ ]. Therefore, the exploration of the correlation between various predictors and intravesical recurrence in patients with UUT-UC after RNU plays a crucial role in clinical comprehensive prevention and treatment, which depend on many kinds of diagnostic techniques[15].

As one of the methods of bladder cancer diagnosis and follow-up, urine abscission cytology has been used for many years. In 1864, Samders discovered cancer cells in the urine of bladder cancer patients, opening the door to urine cytology as a diagnostic tool for bladder cancer $[16,17]$. Due to the characteristics of urine samples, it is always the goal of researchers to obtain high-quality diagnostic results. With the advancement of immunology and molecular biology, many bladder tumor markers have been found over time, which have clinical application value for the early diagnosis and treatment of bladder cancer[18]. Cystoscopy and urine cytology have already become standard for the diagnosis and follow-up of bladder cancer. Previous studies have shown that urine cytology correlates with the prognosis of bladder cancer[19-21].

Although there are studies about urine cytology in the prognosis of intravesical recurrence in UUT-UC patients who underwent RNU[22, 23], the number of studies in mainland Chinese is limited[24, 25]. Moreover, the current role of this modality lacks evidence. In order to draw a persuasive conclusion, we first collected clinical data from UUT-UC patients who underwent RNU to retrospectively evaluate the prognostic value of urine cytology and intravesical recurrence in patients with UUT-UC in China. Then, we conducted a meta-analysis of published literature to systematically explore the role of urine cytology and its effects on postoperative intravesical recurrence.

\section{Materials And Methods}

\section{Study population}

Prior to this study, the information collection and experimental procedures of this study were approved by the institutional review board. In total, from January 2008 to December 2015, 142 patients who were admitted to the Second Affiliated Hospital of Dalian Medical University, Affiliated Dalian Friendship Hospital of Dalian Medical University and Cancer Hospital of China Medical University after UUT-UC was diagnosed and then underwent RNU were chosen and their records examined for a retrospective study. It is worth emphasizing that patients with the following several conditions were excluded from the normative samples: (1) history of prior urothelial carcinoma in the bladder; (2) urothelial carcinoma in both the upper urinary tract and bladder; (3) undergoing attendant cystoprostatectomy; and (4) receiving neoadjuvant chemotherapy or radiotherapy. We extracted the following parameters from the hospital medical records: sex, age, chief complaint, tumor traits including site, stage, grade, laterality, location and focality, status of lymph node, surgery type and adjuvant chemotherapy. Tumor stage was assessed by the 2002 TNM classification of the American Joint Committee on Cancer, and the 1998 WHO/International Society of Urologic Pathology consensus classification was used to evaluate the grades of tumors.

\section{The preoperative evaluation of urine cytology}

Unlike ureteroscopic evaluation with tumor biopsy or retrograde pyelography, preoperative urine cytology should be prioritized if it is necessary to conduct tumor cytology detection. According to the physician's judgment, urine 
samples for cytological examination were collected 1-3 times. In conventional urine cytology, three conditions could be defined: (1) positive urine cytology; (2) suspicious urine cytology; and (3) both. Other cases were all deemed negative samples if they showed negative urine cytology and/or atypical cells. Positive cytology indicated malignancy, while negative cytology indicated benign or normal tissue[26]. The final judgment was confirmed by two pathologists who were blinded to clinical outcomes.

\section{Follow-up and surveillance regimen}

In the first year after the RNU operation, observations were made every 3 months. From the second year to the fifth year, the frequency was slowed down to every 6 months, and once per year thereafter. The measurements of surveillance include serum chemistry studies, routine urine and blood examinations, cystoscopy and various imaging examinations, such as chest plain radiography/CT and radiographic examination of the urinary tract. In addition, the nonsurviving patients' responsible physicians identified the causes of death and then issued chart reviews or death certificates.

\section{Statistical analysis}

The association between preoperative urine cytology and clinicopathological parameters was appraised using Fisher's exact test and the $c^{2}$ test. In order to directly reflect the degree of bladder recurrence after RNU, intravesical recurrence-free survival (IV-RFS), which was defined as the death rate caused by recurrence of UUT-UC after RNU from a recurrent lesion located in the bladder, was used to statistically compare different groups by the log-rank test. Taking various prognostic factors from previous statistics, univariate analysis was used to screen out the most correlated factors $(p<0.05)$. Afterwards, the prognostic factors selected by univariate analysis were subjected to multivariate Cox proportional hazard regression models to compare with each other and filter out the significant factors ( $p$ <0.05). From the direct Kaplan-Meier survival curves drawn from the outcomes of the log-rank test, we compared the ratio of intravesical recurrence-free survival among all the patients and analyzed the survival time of certain cases visually. The aforementioned procedures were done in SPSS version 20.0 (SPSS Inc, Chicago, USA). To identify the independent risk factors for moderate/severe preoperative urine cytology, nomogram plot was programmed with $\mathrm{R}$ software (R Foundation for Statistical Computing, Vienna, Austria). The receiver operating characteristic (ROC) curves were plotted to compare the ability of estimate for patient mortality between nomogram and the criteria of score for UT-UUC set by American Joint Commission on Cancer (AJCC). In addition, calibration plot was also drawn in order to evaluate the potential clinical value of the nomogram. The concordance index (Cindex) was calculated by the means of bootstrapping to estimate the probability that the nomogram prognostic models are consistent with the actual observed results. P-value which is less than 0.05 corresponds with statistically significant.

\section{Meta-analysis}

\section{Search Strategy}

We assessed the pertinence of outcomes of preoperative urine cytology and the prognosis of UUT-UC after RNU by searching the PubMed, Medline, Embase, Cochrane Library and Scopus databases. The following retrieved words and medical subject headings that included all spellings were used: "Urine cytology”, "Upper urinary tract”, "Renal pelvis”, “Ureter”, “Urothelial cancer”, “Urothelial carcinoma”, “Bladder cancer”, and "Prognosis”. "Recurrence”, "Intravesical". Additionally, we manually searched further eligible bibliographies and company reports to ensure the 
comprehensiveness of the experimental data from the literature. The publication country and time were not restricted.

\section{Selection Criteria}

The following criteria were used to measure whether or not valuable literature was collected. Inclusion criteria: (1) upper urothelial carcinoma was the histologic type; (2) selected samples had the corresponding data of preoperative urine cytology; and (3) the relationship between preoperative abscission urine cytology and postoperative IRFS was analyzed. The exclusion criteria were as follows: (1) studies that lacked original data, including reviews, letters to the editor, commentaries, and case reports; (2) studies containing data from earlier studies; (3) articles written by the same authors as another, chosen article; (4) studies without original data or no record of intravesical recurrence-free survival; and (5) studies with invalid data for calculating the hazard ratio (HR) and its standard error.

\section{Data extraction}

According to the aforementioned criteria, two investigators undertook a rigorous process to improve reliability and minimize bias. A third reviewer (Xishang Song) examined the extracted results and eliminated any discrepancies between the independent search results. If a study appeared appropriate, the full text was reviewed. The study was considered relevant if it met the inclusion criteria. Finally, 11 eligible articles[22, 24-33] from 2010 to 2016 was selected. The primary information the investigators recorded included author, publication year, region, study type, recruitment period, number of patients, baseline characteristics (mean age and sex, etc.), evaluation of positive urine cytology and so forth. The secondary information, based on the above-mentioned data, such as HRs and $95 \%$ confidence intervals (Cls) of IRFS, was also statistically analyzed.

\section{Statistical analysis}

The dichotomous outcomes were compared by assessment of HRs with $95 \% \mathrm{Cls}$. The $\mathrm{c}^{2}$ test was used to qualitatively analyze heterogeneity. If the heterogeneity $p$-value was $<0.05$, a random-effect model rather than the fixed-effect model was employed. The $\mathrm{I}^{2}$ test was used to quantitatively delineate heterogeneity and measure the percentage of volatility. If $\mathrm{I}^{2}>50 \%$, there was heterogeneity between studies. Subgroup analysis by Begg's test and Egger's test was visually reflected by forest and funnel plots to represent the estimated pooled effect using the Mantel-Haenszel random-effect model and to assess the publication bias. If the diamond crossed the vertical median line, statistical significance was confirmed. All statistical analyses were performed using Stata 12.0 (Stata Corporation, College Station, TX, USA).

\section{Results}

\section{Case-control study}

\section{Relationship between examination of urine cytology and the clinicopathological characteristics of UUT-UC patients}

In order to investigate the clinical relationship between the outcomes of urine cytology and intravesical recurrence after radical nephroureterectomy in UUT-UC patients, we redivided our patients into two groups: the preoperative positive urine cytology group and the preoperative negative urine cytology group. The descriptive clinicopathological characteristics of the 142 patients (sex, age, tumor side, tumor location, tumor focality, pathological stage, histological grade, lymph node status, distant metastasis, and type of operation) are listed in Table 1. In total, there were 68 patients (47.9\%) with positive urine cytology. The sex composition was 86 males and 70 females. There 
was no significant difference between groups in the outcome of urine cytology or in clinicopathological factors, including tumor side, histological grade, lymph node status, type of operation, etc. The primary tumors were located in the calix or pelvis in $57.0 \%(n=81)$ of patients, and multifocal tumors were present in 18 patients $(12.7 \%)$. Positive lymph nodes were present in 11 patients (7.8\%), and distant metastases were present in 2 patients $(1.4 \%)$.

Pathological stage was the only variable positively correlated with preoperative positive urine cytology $(p=0.001)$. By Spearman's correlation analysis, the correlation coefficient was $0.289(p<0.001)$ between preoperative positive urine cytology and pathological stage, indicating that preoperative positive urine cytology may be associated with the aggressive form of UUT-UC.

Table 1 Demographics and clinicopathologic characteristics of 142 patients treated with RNU for UUT-UC Total P Value

\begin{tabular}{|c|c|c|c|c|}
\hline & \multicolumn{2}{|c|}{ Preoperative urine cytology } & & \\
\hline & Negative group & Positive group & & \\
\hline Gender & & & & 0.536 \\
\hline Male & 43 & 36 & 79 & \\
\hline Female & 31 & 32 & 63 & \\
\hline Age, years & & & & 0.064 \\
\hline Less than 69 & 42 & 28 & 72 & \\
\hline 69 or Greater & 32 & 40 & 72 & \\
\hline Tumor side & & & & 0.258 \\
\hline Right & 44 & 34 & 78 & \\
\hline Left & 30 & 34 & 64 & \\
\hline Tumor location & & & & 0.511 \\
\hline Calix or pelvis & 40 & 41 & 81 & \\
\hline Ureter & 29 & 25 & 54 & \\
\hline More than 1 & 5 & 2 & 7 & \\
\hline Tumor focality & & & & 0.848 \\
\hline Unifocal & 65 & 59 & 124 & \\
\hline Mutifocal & 9 & 9 & 18 & \\
\hline Pathologic stage & & & & 0.001 \\
\hline Tis-T1 & 43 & 20 & 63 & \\
\hline $\mathrm{T} 2-\mathrm{T} 4$ & 31 & 48 & 79 & \\
\hline Histological grade & & & & 0.850 \\
\hline Low & 25 & 24 & 49 & \\
\hline High & 49 & 44 & 93 & \\
\hline Lymph node status & & & & 0.159 \\
\hline No & 71 & 60 & 131 & \\
\hline $\mathrm{N}_{1}$ & 3 & 6 & 9 & \\
\hline $\mathrm{Nx}$ & 0 & 2 & 2 & \\
\hline Distant metastasis & & & & 0.172 \\
\hline $\mathrm{M}_{0}$ & 72 & 68 & 140 & \\
\hline $\mathrm{M}_{1}$ & 2 & 0 & 2 & \\
\hline Type of surgery & & & & 0.786 \\
\hline Open & 58 & 52 & 110 & \\
\hline Laparoscopic & 16 & 16 & 32 & \\
\hline
\end{tabular}


To determine whether preoperative urine cytology is a significant predictor of bladder cancer recurrence after radical nephroureterectomy, Kaplan-Meier curves were calculated to determine the relationships between positive or negative preoperative urine cytology and bladder cancer recurrence (Fig. 1). The intravesical recurrence-free survival of patients with preoperative positive urine cytology was significantly lower than that of patients with preoperative negative urine cytology $(\mathrm{p}<0.001)$. In univariate Cox regression analysis, the following factors showed statistical significance: preoperative urine cytology $(\mathrm{HR}=3.47,95 \% \mathrm{Cl}=1.67-7.24, \mathrm{p}=0.001)$, histological grade $(\mathrm{HR}=2.83,95 \%$ $\mathrm{Cl}=1.18-6.81, \mathrm{p}=0.020)$ and lymph node status $(\mathrm{HR}=2.64,95 \% \mathrm{Cl}=1.38-5.05, \mathrm{p}=0.003)$. On multivariate analysis, preoperative urine cytology $(\mathrm{HR}=3.24,95 \% \mathrm{Cl}=1.54-6.83, \mathrm{p}=0.002)$ and lymph node status $(\mathrm{HR}=2.67,95 \% \mathrm{Cl}=1.10-$ $6.47, p=0.030$ ) were validated as independent predictors correlated with intravesical recurrence. The outcomes of univariate and multivariate analysis were shown on Table 2.

\begin{tabular}{|c|c|c|c|c|c|}
\hline \multirow{2}{*}{\multicolumn{2}{|c|}{$\begin{array}{c}\text { treated with RNU for UUT-UC } \\
\text { Characteristic }\end{array}$}} & \multicolumn{2}{|l|}{ Univariate } & \multicolumn{2}{|c|}{ Multivariate } \\
\hline & & HR & p Value & HR & p Value \\
\hline & Gender & $1.578(0.816-3.053)$ & 0.175 & & \\
\hline & Age & $1.706(0.872-3.337)$ & 0.119 & & \\
\hline & Preoperative urine cytology & $3.474(1.668-7.236)$ & 0.001 & $3.243(1.540-6.829)$ & 0.002 \\
\hline & Tumor laterality & $1.286(0.668-2.473)$ & 0.451 & & \\
\hline & Tumor location & $0.963(0.559-1.657)$ & 0.891 & & \\
\hline & Tumor focality & $0.935(0.363-2.407)$ & 0.889 & & \\
\hline & Pathologic stage & $1.075(0.555-2.084)$ & 0.830 & & \\
\hline & Histological grade & $2.832(1.177-6.811)$ & 0.020 & $2.668(1.100-6.471)$ & 0.030 \\
\hline & Lymph node status & $2.643(1.382-5.054)$ & 0.003 & $1.806(0.933-3.496)$ & 0.079 \\
\hline & Distant metastasis & $2.287(0.311-16.807)$ & 0.416 & & \\
\hline & Type of surgery & $0.852(0.372-1.952)$ & 0.705 & & \\
\hline
\end{tabular}

\section{Nomogram of prognostic prediction based on the preoperative urine cytology}

Using $\mathrm{R}$ language, we combined preoperative urine cytology, age, gender, tumor side, tumor location, tumor focality, histological grade, pathologic stage, lymph node status, distant metastasis, and surgery type to establish a novel nomogram, as shown in Fig. 2. The clinician can locate the data on the nomogram, sum the score up and get a total prognostic point. The 1-, 3- and 5-year OS rates of UT-UUC patients can be converted accordingly. The calibration plots was demonstrated in Fig. 3. We have observed that, in comparison with the prediction of 5-year OS, the actual curves made by using the nomogram in the prediction of 1- and 3-year OS have a better coincidence with the ideal curves. The AUCs of ROC curves of 1-, 3 - and 5-year nomograms which are respectively $0.67(95 \% \mathrm{Cl}=0.65-0.83)$, $0.76(95 \% \mathrm{Cl}=0.66-0.84)$ and $0.74(95 \% \mathrm{Cl}=0.65-0.83)$ also revealed better discrimination by the nomogram than AJCC score (Fig. 4) . The model C-index and the internally verified C-index respectively equal to 0.75 and 0.68. Therefore, we could speculate that the aforementioned nomogram prognostic model has a significant potential to predict 1-, 3- and 5-year OS.

\section{Meta-analysis of the correlation between preoperative positive urine cytology and the risk of intravesical recurrence in UUT-UC patients}

\section{Method of systematic selection of relevant publications}

The detailed process of selection is shown in Fig. 5. A total of 339 initial studies were identified from electronic database and literature searches, and additional records were found from other approaches $(n=3)$. After the duplicated publications were removed $(n=114)$ and we manually screened the titles and abstracts $(n=87), 27$ studies were left. With the careful assessment of the remaining studies based on the information from the title, abstract, and 
full text, those that had HRs or 95\% Cls that could not be extracted, those that were irrelevant to our analysis (such as papers on extravesicular recurrence, lower urothelial neoplasm or nonurinary carcinoma, etc.), reviews, commentaries, and animal studies were excluded $(n=16)$. Eleven candidate studies remained. We have accepted no different studies from the same group. Adding these to our cohort study $(n=1), 12$ independent articles including quantitative synthesis were finally included in our meta-analysis. The major characteristics of the twelve included studies are summarized in Table 3. They were published from 2010 to 2016 . One of the studies assessed patients from within Korea[22], 3 from China[24, 25], and 8 from Japan[26-33]. Only one study was an RCT[30], 4 were casecontrol[22, 27, 31, 32] studies, and the others were retrospective cohort searches[24-26, 28, 29, 33]. The size of the studies varied from 36 to 754, with a total number of 2942 patients. The mean or median follow-up duration varied from 8.4 to 69.3 years. Only one publication did not provide the recruitment period, and demographics of only one publication were missing. Six studies showed the assessment of positive urine cytology.

\section{Table 3 Main characteristics of ten studies included in the meta-analysis.}




\begin{tabular}{|c|c|c|c|c|c|c|c|c|}
\hline $\begin{array}{l}\text { First } \\
\text { author } \\
\text { (year) }\end{array}$ & Country & Study type & $\begin{array}{l}\text { Recruitment } \\
\text { period }\end{array}$ & $\begin{array}{l}\text { Follow- } \\
\text { up }_{\text {(months) }}\end{array}$ & $\begin{array}{l}\text { No. of } \\
\text { subjects }\end{array}$ & $\begin{array}{c}\text { Demographics } \\
\text { (mean age, } \\
\text { sex) }\end{array}$ & $\begin{array}{l}\text { Assessment of } \\
\text { positive urine } \\
\text { cytology }\end{array}$ & $\begin{array}{l}\text { Reported } \\
\text { endpoints }\end{array}$ \\
\hline \multirow[t]{2}{*}{$\begin{array}{l}\text { Long X } \\
\text { (2016) }\end{array}$} & China & $\begin{array}{c}\text { Cohort; } \\
\text { Retrospective }\end{array}$ & $2004-2012$ & $\begin{array}{l}52 \\
(38.0- \\
68.0)\end{array}$ & 159 & $\begin{array}{c}62.0 \\
M: F=113: 46\end{array}$ & NR & $\begin{array}{c}2.173 \\
(1.084- \\
4.350)\end{array}$ \\
\hline & & & & & 161 & $\begin{array}{c}60.8 \\
M: F=120: 41\end{array}$ & & $\begin{array}{l}1.143 \\
(0.544- \\
2.400)\end{array}$ \\
\hline $\begin{array}{l}\text { Ishioka J } \\
\text { (2015) }\end{array}$ & Japan & $\begin{array}{c}\text { Cohort; } \\
\text { Retrospective }\end{array}$ & $1995-2010$ & $\begin{array}{c}41 \\
(18-75)\end{array}$ & 754 & $\begin{array}{c}69 \\
M: F=526: 228\end{array}$ & NR & $\begin{array}{l}1.259 \\
(0.926- \\
1.711)\end{array}$ \\
\hline $\begin{array}{l}\text { Narukawa } \\
\mathrm{T}(2015)\end{array}$ & Japan & $\begin{array}{c}\text { Case control } \\
\text { Retrospective }\end{array}$ & 1995-2012 & $\begin{array}{c}71 \\
(0.8- \\
210.8)\end{array}$ & 133 & $\begin{array}{c}66 \\
M: F=101: 32\end{array}$ & NR & $\begin{array}{l}1.080 \\
(0.630- \\
1.850)\end{array}$ \\
\hline $\begin{array}{l}\text { Fang D } \\
(2014)\end{array}$ & China & $\begin{array}{c}\text { Cohort; } \\
\text { Retrospective }\end{array}$ & $2000-2010$ & $\begin{array}{c}45 \\
(12-144)\end{array}$ & 438 & $\mathrm{M}: \mathrm{F}=187: 251$ & $\begin{array}{c}\text { Indicative } \\
\text { of malignancy and } \\
\text { the presence of } \\
\text { atypical cells that } \\
\text { were highly } \\
\text { suggestive of } \\
\text { urothelial } \\
\text { carcinoma }\end{array}$ & $\begin{array}{l}1.160 \\
(0.810- \\
1.660)\end{array}$ \\
\hline $\begin{array}{l}\text { Shibuya T } \\
\text { (2014) }\end{array}$ & Japan & $\begin{array}{c}\text { Cohort; } \\
\text { Retrospective }\end{array}$ & $2002-2012$ & $\begin{array}{c}30.2 \\
(5-142)\end{array}$ & 54 & NR & $\mathrm{NR}$ & $\begin{array}{l}2.680 \\
(1.110- \\
6.450)\end{array}$ \\
\hline $\begin{array}{l}\text { Cho DS } \\
\text { (2013) }\end{array}$ & Korea & $\begin{array}{c}\text { Case control } \\
\text { Retrospective }\end{array}$ & $2004-2012$ & $\begin{array}{l}34.0 \\
(12.0- \\
132.0)\end{array}$ & 78 & $\begin{array}{c}65 \\
M: F=58: 20\end{array}$ & $\begin{array}{c}\text { Class } 4 \text { or } 5 \\
\text { findings according } \\
\text { to the } \\
\text { Papanicolaou } \\
\text { classification }\end{array}$ & $\begin{array}{l}4.606 \\
(1.450- \\
14.633)\end{array}$ \\
\hline $\begin{array}{c}\text { Ito A } \\
\text { (2013) }\end{array}$ & Japan & $\mathrm{RCT}$ & NR & $\begin{array}{l}8.4 \\
(3.0- \\
30.1)\end{array}$ & 36 & $\begin{array}{c}69 \\
M: F=43: 29\end{array}$ & $\begin{array}{c}\text { At least one } \\
\text { positive finding } \\
\text { among multiple } \\
\text { examinations }\end{array}$ & $\begin{array}{l}5.540 \\
(1.120- \\
27.500)\end{array}$ \\
\hline $\begin{array}{c}\text { Tanaka N } \\
\text { (2013) }\end{array}$ & Japan & $\begin{array}{c}\text { Cohort; } \\
\text { Retrospective }\end{array}$ & 1994-2010 & $\begin{array}{l}35.0 \\
(17.0- \\
68.0)\end{array}$ & 474 & $\begin{array}{c}69 \\
M: F=346: 128\end{array}$ & $\begin{array}{l}\text { One that reported } \\
\text { suspicious or } \\
\text { positive results, } \\
\text { or both }\end{array}$ & $\begin{array}{l}1.410 \\
(1.080- \\
1.850)\end{array}$ \\
\hline $\begin{array}{c}\text { Kobayashi } \\
\text { Y } \\
(2012)\end{array}$ & Japan & Case control & $2005-2009$ & $\begin{array}{l}20.2 \\
(3.0- \\
61.6)\end{array}$ & 288 & $\begin{array}{c}71.4 \\
M: F=197: 91\end{array}$ & NR & $\begin{array}{l}1.977 \\
(1.310- \\
2.983)\end{array}$ \\
\hline $\begin{array}{l}\text { Hirano D } \\
(2012)\end{array}$ & Japan & $\begin{array}{c}\text { Cohort; } \\
\text { Retrospective }\end{array}$ & $1995-2010$ & $\begin{array}{c}24 \\
(3.0- \\
162.0)\end{array}$ & 151 & $\begin{array}{c}68 \\
M: F=121: 30\end{array}$ & NR & $\begin{array}{c}0.948 \\
(0.498- \\
1.807)\end{array}$ \\
\hline $\begin{array}{l}\text { Takaoka } \\
\text { E (2010) }\end{array}$ & Japan & $\begin{array}{l}\text { Case control } \\
\text { Retrospective }\end{array}$ & 1989-2007 & $\begin{array}{c}69.3 \\
(1.5- \\
223.8)\end{array}$ & 60 & $\begin{array}{c}64.7 \\
\mathrm{M}: \mathrm{F}=40: 20\end{array}$ & $\begin{array}{l}\text { Appearance of } \\
\text { voiding urine } \\
\text { cytology }\end{array}$ & $\begin{array}{l}1.560 \\
(0.481- \\
5.053)\end{array}$ \\
\hline This study & China & $\begin{array}{c}\text { Cohort; } \\
\text { Retrospective }\end{array}$ & $2006-2013$ & $\begin{array}{l}41.3 \\
(4.2- \\
106.5)\end{array}$ & 156 & $\begin{array}{c}68 \\
M: F=86: 70\end{array}$ & $\begin{array}{l}\text { One that reported } \\
\text { suspicious or } \\
\text { positive results, } \\
\text { or both }\end{array}$ & $\begin{array}{l}3.365 \\
(1.646- \\
6.879)\end{array}$ \\
\hline
\end{tabular}

\section{Overall analysis}

Forest plots are depicted in Fig. 6, which presents the relative risk estimates from 12 studies for the relationship between preoperative urine cytology and intravesical recurrence. A random-effect model was selected because significant heterogeneity was detected $\left(\mathrm{I}^{2}=45.3 \%, \mathrm{p}=0.038\right)$. Overall analysis showed that the combined HR was 1.56 $(95 \% \mathrm{Cl}=1.26-1.93, \mathrm{p}<0.001)$, suggesting that preoperative positive urine cytology was associated with a $56 \%$ increased risk of intravesical recurrence. Visually, the shape of Begg's funnel plots (Fig. 8) revealed evidence of obvious asymmetry (Begg's test, $z=0.028$ ). Statistically, the positive result in Egger's test indicated moderate publication bias $(\mathrm{p}=0.008)$.

\section{Subgroup analysis}


In the subgroup analysis by region, the random-effect model was applied. A significant difference was noted between the Japan subgroup $(\mathrm{HR}=1.45,95 \% \mathrm{Cl}=1.16-1.81, \mathrm{p}=0.001)$ and the China subgroup $(\mathrm{HR}=1.66,95 \% \mathrm{Cl}=1.02-$ $2.71, p=0.042)$, which suggests that preoperative positive urine cytology increased the risk of intravesical recurrence by $45 \%$ in Japan and $66 \%$ in China. In addition, under the random-effect model, there was precise evidence that preoperative positive urine cytology was related to an increase in intravesical recurrence, not only in the subgroup of the cohort studies $(\mathrm{HR}=1.44,95 \% \mathrm{Cl}=1.15-1.80, \mathrm{p}<0.001)$ but also in the subgroup of the case-control studies $(\mathrm{HR}=1.77,95 \% \mathrm{Cl}=1.06-2.93, \mathrm{p}=0.028)$. In the subgroup analysis by sample size, when the sample size was 100 or more, the risk of intravesical recurrence was 1.42 times higher in patients with positive urine cytology than in those with negative cytology $(95 \% \mathrm{Cl}=1.16-1.73, \mathrm{p}=0.001)$. When the sample size was less than 100 , the same trend was seen $(\mathrm{HR}=2.95,95 \% \mathrm{Cl}=1.68-5.17, \mathrm{p}<0.001)$. To explore whether the assessment of urine cytology influenced preoperative urine cytology and intravesical recurrence, subgroup analysis was done under a random-effect model. The results showed that preoperative positive urine cytology was associated with an increase in intravesical recurrence, not only in the group with assessment of urine cytology $(\mathrm{OR}=1.96 ; 95 \% \mathrm{Cl}=1.23-3.13 ; \mathrm{p}=0.005)$ but also in the group without assessment of urine cytology $(\mathrm{OR}=1.44 ; 95 \% \mathrm{Cl}=1.14-1.83 ; \mathrm{p}=0.002)$. Fig. 7 has shown all the forest plots.

\section{Discussion}

The ratio of intravesical recurrence has ranged from $22 \%$ to $50 \%$ in patients with UUT-UC who underwent RNU in most studies[34]. In our study, intravesical recurrence was seen in $24.3 \%$ of samples and usually occurred within 33.1 months after surgery. Therefore, we think that the postoperative follow-up within 2 years should be strengthened. In our univariate analysis, we found that preoperative urine cytology and lymph node status were significant factors for recurrence of bladder cancer. In the multivariate analysis, they were still independent risk factors for bladder cancer recurrence in the future. Pathological stage was the only variable positively correlated with preoperative positive urine cytology $(p=0.001)$. In fact, as various risk factors correlated with intravesical recurrence have been found and analyzed, studies differ significantly in the identification of multifactorial prognosis. For patients with UUT-UC, a history of bladder cancer, tumor location in the ureter or tumor multifocality have been validated as prognostic factors in the recurrence of non-muscle-invasive bladder cancer[35-37]. The number of patients with multiple upper urothelial carcinomas who had recurrent urothelial carcinomas was significantly higher than that of patients with single urothelial carcinomas[38]. In addition, tumor size, preoperative hydronephrosis and ureterorenoscopy are more likely to lead to postoperative recurrence in the bladder[39-41]. Some of those conclusions are consistent with ours. The differences among studies explain the diversity of characteristics of urothelial carcinoma and have led to uncertainties in clinical follow-up and treatment, which should be studied further in long-term, systematic, large-sample research.

In our meta-analysis of 11 published studies[22, 24-33] and our case-control study, preoperative positive urine cytology was associated with a $56 \%$ increased risk of intravesical recurrence ( $\mathrm{HR}=1.56,95 \% \mathrm{Cl}=1.26-1.93)$, not only in the subgroup of cohort studies $(\mathrm{HR}=1.44,95 \% \mathrm{Cl}=1.15-1.80)$ but also in the subgroup of case-control studies $(\mathrm{HR}=1.77,95 \% \mathrm{Cl}=1.06-2.93)$. Interestingly, there is an attractive hypothesis that can explain the mechanism of urinary abscission cytology in the prediction of recurrence in the bladder after upper urothelial neoplasms. In a previous study, the dissemination and floating of cancer cells from UUT-UC in the bladder occurred postoperatively[42, 43]. During radical nephroureterectomy, the bladder is cut open, and a urethral catheter is placed, resulting in an increased degree of bladder exposure. Injured urothelium is more likely to provide a site for adherence compared with complete urothelium. Along with continuously monitoring the removal of postoperative remnants, 
urinary bladder suspensions can be used to determine whether tumor cells have adhered to the damaged urothelium and proliferated[44, 45].

In fact, tumors can occur in one or more sites simultaneously or at different times. Recurrent bladder cancer after upper urinary tract urothelial carcinoma is a kind of multiple-organ carcinoma of the urinary tract epithelium[46, 47]. It is universally acknowledged that the polycentricity of lesions plays an important role in the biological characteristics of urothelial carcinoma[43,45,47]. Based on our findings and implantation theory, it seems that urothelial multiorgan carcinoma originates from the same cell clone. According to this view, urothelial carcinoma originates from a single cell clone, and urothelial multiorgan carcinoma is caused by tumor cell implanting along the direction of urine flow and migrating intraepithelially to form multiple tumor lesions[43, 48]. Many conditions can be explained by implantation theory, such as unilateral upper urinary tract urothelial carcinoma, tumors formed in the same direction as urine flow and consistent tumor histologic patterns in multiple organs.

From the perspective of tumorigenesis, another theory is the multifocal origin theory. The polycentricity of urothelial carcinoma is caused by chromosome deletion and gene mutation of normal cells under the action of local carcinogenic factors, forming independent cell clones. These clones proliferate to produce multiple tumor lesions at the same or different times. This theory can explain the bilateral upper urinary tract tumors appearing at the same or different times and the long-term neoplasms that occur in the same direction. Some scholars still emphasize that intravesical recurrence, even a multiorgan carcinoma in the reverse direction from urinary flow, is related to tumor cell implantation. In fact, studies have reported that multiple or recurrent urothelial carcinomas probably arise from the same tumor cell implantation rather than from multicentric tumors[43, 47]. From clinical observations, the incidence of upper urinary tract urothelial carcinoma after bladder cancer is lower than that of upper urinary tract urothelial carcinoma followed by bladder cancer. It was further confirmed that the mechanism of recurrence of bladder tumors in patients with UUT-UC is related to cystoureteral reflux. In summary, tumor cell implantation may be the main cause of recurrent bladder cancer after urothelial carcinoma and is worthy of further study[46, 49].

Although we did a case-control study and meta-analysis of the data in the published literature to overcome the limitation of our single-center sample source to some extent and to further confirm the accuracy of our research results, our study has some potential limitations. First, our sample was enrolled from only one affiliated hospital of a medical university, restricting the universality of our retrospective findings. Additionally, the different surgeons used different surgical procedures, which could lead to certain errors. Compared with multicenter data, the sample size of single-center data is limited, which causes certain limitations in the statistical analysis of predictors. The metaanalysis results also have some defects. Although we searched for literature from multiple sources, even including unpublished trials and abstracts that can cause higher risks of null results, we could not refrain from the potential bias. Publication bias might have been caused by several things: (1) In these articles, we selected the hazard ratios from multivariate survival analysis. Univariate data will be adopted when the available results emerge. (2) If HRs and their variance were not reported, we performed a calculation from the survival comparison statistics and its variance, which has less reliability than direct data[50-52]. In addition, because of the differences in the diagnostic criteria for urinary cytology among different countries and regions, the quality of this study would have been improved by standardized protocols.

\section{Conclusion And Outlook}

With the development of molecular biology approaches, the processes of urothelial carcinoma pathogenesis have been widely and deeply explored. We have classified bladder cancer by gene sequencing and comprehensive

Page $11 / 24$ 
profiling of RNA expression and have used DNA sequencing results from biopsy to understand survival distributions and prognostic factors[53-55]. This new understanding of heterogeneous diseases such as UT-UUC and bladder cancer can lead to improved outcomes and quality of life through better-customized treatments. For positive tumor cells and moderately or severely abnormal cells, significant differences in genes arise as the disease occurs and progresses. Therefore, we predict that the genetic analysis of exfoliated cells in urine may be helpful for making new discoveries on the evolution of urinary tract tumors. In addition, in cancer pathological states, abnormal activation of export machinery, such as exosomes (products of vesicular transport), results in excessive discharge of many key proteins and misexpression of miRNAs, which are molecules with great differences in size[56, 57]. mRNA expression analysis is an effective tumor phenotyping tool that has been used to define the molecular subtypes of almost every major tumor type[58]. It is worth focusing on the key molecular processes and analyzing gene and protein expression systematically. We believe that successful exploration of cancer therapeutic targets requires an interdisciplinary understanding of these cellular activating or inhibiting mechanisms and how secreted biomolecules participate in cell-cell interactions in the tumor microenvironment.

\section{Abbreviations}

UUT-UC: upper urinary tract urothelial carcinoma; RNU: radical nephroureterectomy; IV-RFS: intravesical recurrencefree survival; ROC curve: receiver operating characteristic curve; C-index: concordance index; AJCC: American Joint Commission on Cancer; HR: hazard ratio; OR: odd ratio; Cl: confidence interval.

\section{Declarations}

\section{Acknowledgements}

This work was supported by the Second Affiliated Hospital of Dalian Medical University, Affiliated Dalian Friendship Hospital of Dalian Medical University and Cancer Hospital of China Medical University. The authors would like to thank all members of the study team, the patient and their family.

\section{Authors' contributions}

WS, TQ-L and HS-Z collected and analyzed the patient' s clinical data and designed the research; XZ and HD-J performed and interpreted pathology staining; MS, ZF-Y and LH performed the review of literature and drafted the manuscript; BF, WS, TQ-L, ZN and RZ performed molecular analyses; BF and HS-Z assisted with image interpretation and formatting and critically revised the manuscript. All authors have read and approved the final version of the manuscript.

\section{Funding}

Our study was granted by the National Natural Science Foundation of China $(31800787 ; 81902498)$, the Natural Science Foundation of Liaoning Province (LQ2017025), the Doctoral Research Startup Foundation of Liaoning Province (20180540020), the Medical Scientific Research Project of Dalian City (1812038), Natural Science Foundation of Hubei Province of China (2019CFB177), Natural Science Foundation of Hubei Provincial Department of Education (Q20182105), Chen Xiao-ping Foundation for the development of science and technology of Hubei Provincial (CXPJJH11800001-2018333) and Innovation and entrepreneurship training program (201810929005; 201810929009; 201810929068; 201813249010).

\section{Availability of data and materials}

Page $12 / 24$ 
All data generated or analysed during this study are within the published article.

\section{Ethics approval and consent to participate}

Ethical approval was granted by the Ethical Review Board of the Second Affiliated Hospital of Dalian Medical University (KY 2018-001).

\section{Consent for publication}

Not applicable.

\section{Competing interests}

The authors declare no conflict of interest.

\section{References}

1. Singla N, Fang D, Su X, Bao Z, Cao Z, Jafri SM, et al. A Multi-Institutional Comparison of Clinicopathological Characteristics and Oncologic Outcomes of Upper Tract Urothelial Carcinoma in China and the United States. J Urol. 2017;197(5):1208-13.

2. Audenet F, Isharwal S, Cha EK, Donoghue M, Drill EN, Ostrovnaya I, et al. Clonal Relatedness and Mutational Differences between Upper Tract and Bladder Urothelial Carcinoma. Clin Cancer Res. 2019;25(3):967-76.

3. Chen CS, Li JR, Wang SS, Yang CK, Cheng CL, Yang CR, et al. Tumor Multifocality is a Significant Risk Factor of Urinary Bladder Recurrence after Nephroureterectomy in Patients with Upper Tract Urothelial Carcinoma: A Single-Institutional Study. Diagnostics (Basel). 2020;10(4).

4. Chen CC, Hsieh TF, Huang CP, Yu AL, Chang WL, Shyr CR. Androgen receptor expands the population of cancer stem cells in upper urinary tract urothelial cell carcinoma cells. Am J Cancer Res. 2016;6(2):238-48.

5. Baboudjian M, Al-Balushi K, Michel F, Lannes F, Akiki A, Gaillet S, et al. Diagnostic ureteroscopy prior to nephroureterectomy for urothelial carcinoma is associated with a high risk of bladder recurrence despite technical precautions to avoid tumor spillage. World J Urol. 2020;38(1):159-65.

6. Clements MB, Krupski TL, Culp SH. Robotic-Assisted Surgery for Upper Tract Urothelial Carcinoma: A Comparative Survival Analysis. Ann Surg Oncol. 2018;25(9):2550-62.

7. Xylinas E, Rink M, Cha EK, Clozel T, Lee RK, Fajkovic H, et al. Impact of distal ureter management on oncologic outcomes following radical nephroureterectomy for upper tract urothelial carcinoma. Eur Urol. 2014;65(1):210-7.

8. Moss TJ, Qi Y, Xi L, Peng B, Kim TB, Ezzedine NE, et al. Comprehensive Genomic Characterization of Upper Tract Urothelial Carcinoma. Eur Urol. 2017;72(4):641-9.

9. Rouprêt M, Babjuk M, Burger M, Capoun O, Cohen D, Compérat EM, et al. European Association of Urology Guidelines on Upper Urinary Tract Urothelial Carcinoma: 2020 Update. Eur Urol. 2020.

10. Seisen T, Granger B, Colin P, Léon P, Utard G, Renard-Penna R, et al. A Systematic Review and Meta-analysis of Clinicopathologic Factors Linked to Intravesical Recurrence After Radical Nephroureterectomy to Treat Upper Tract Urothelial Carcinoma. Eur Urol. 2015;67(6):1122-33.

11. Zhong W, Zhang L, Ma J, Shao S, Lin R, Li X, et al. Impact of aristolochic acid exposure on oncologic outcomes of upper tract urothelial carcinoma after radical nephroureterectomy. Onco Targets Ther. 2017;10:5775-82. 
12. Fang D, Zhang L, Li X, Yu W, Singla N, Zhao G, et al. Presence of Concomitant Non-muscle-invasive Bladder Cancer in Chinese Patients with Upper Tract Urothelial Carcinoma: Risk Factors, Characteristics, and Predictive Value. Ann Surg Oncol. 2015;22(8):2789-98.

13. Fan B, Hu B, Yuan Q, Wen S, Liu T, Bai S, et al. Impact of tumor architecture on disease recurrence and cancerspecific mortality of upper tract urothelial carcinoma treated with radical nephroureterectomy. Tumour Biol. 2017;39(7):1010428317710822.

14. Huang YC, Chang YH, Chiu KH, Shindel AW, Lai CH. Adjuvant radiotherapy for locally advanced upper tract urothelial carcinoma. Sci Rep. 2016;6:38175.

15. Peyronnet B, Seisen T, Dominguez-Escrig JL, Bruins HM, Yuan CY, Lam T, et al. Oncological Outcomes of Laparoscopic Nephroureterectomy Versus Open Radical Nephroureterectomy for Upper Tract Urothelial Carcinoma: An European Association of Urology Guidelines Systematic Review. Eur Urol Focus. 2019;5(2):20523.

16. PAPANICOLAOU GN. Cytology of the urine sediment in neoplasms of the urinary tract. J Urol. 1947;57(2):375-9.

17. JOHNSON WD. CYTOPATHOLOGICAL CORRELATIONS IN TUMORS OF THE URINARY BLADDER. Cancer. 1964;17:867-80.

18. Faiena I, Rosser CJ, Chamie K, Furuya H. Diagnostic biomarkers in non-muscle invasive bladder cancer. World J Urol. 2019;37(10):2009-16.

19. Soria F, D'Andrea D, Pohar K, Shariat SF, Lotan Y. Diagnostic, prognostic and surveillance urinary markers in nonmuscle invasive bladder cancer: any role in clinical practice. Curr Opin Urol. 2018;28(6):577-83.

20. Lodewijk I, Dueñas M, Rubio C, Munera-Maravilla E, Segovia C, Bernardini A, et al. Liquid Biopsy Biomarkers in Bladder Cancer: A Current Need for Patient Diagnosis and Monitoring. Int J Mol Sci. 2018;19(9).

21. Zhan Y, Du L, Wang L, Jiang X, Zhang S, Li J, et al. Expression signatures of exosomal long non-coding RNAs in urine serve as novel non-invasive biomarkers for diagnosis and recurrence prediction of bladder cancer. Mol Cancer. 2018;17(1):142.

22. Cho DS, Kim SI, Ahn HS, Kim SJ. Predictive factors for bladder recurrence after radical nephroureterectomy for upper urinary tract urothelial carcinoma. Urol Int. 2013;91(2):153-9.

23. Dev HS, Poo S, Armitage J, Wiseman O, Shah N, Al-Hayek S. Investigating upper urinary tract urothelial carcinomas: a single-centre 10-year experience. World J Urol. 2017;35(1):131-8.

24. Long X, Zu X, Li Y, He W, Hu X, Tong S, et al. Epidermal Growth Factor Receptor and Ki-67 as Predictive Biomarkers Identify Patients Who Will Be More Sensitive to Intravesical Instillations for the Prevention of Bladder Cancer Recurrence after Radical Nephroureterectomy. PLoS One. 2016;11(11):e0166884.

25. Fang D, Xiong GY, Li XS, Chen XP, Zhang L, Yao L, et al. Pattern and risk factors of intravesical recurrence after nephroureterectomy for upper tract urothelial carcinoma: a large Chinese center experience. J Formos Med Assoc. 2014;113(11):820-7.

26. Tanaka N, Kikuchi E, Kanao K, Matsumoto K, Shirotake S, Kobayashi H, et al. The predictive value of positive urine cytology for outcomes following radical nephroureterectomy in patients with primary upper tract urothelial carcinoma: a multi-institutional study. Urol Oncol. 2014;32(1):48.e19-26.

27. Narukawa T, Hara T, Arai E, Komiyama M, Kawahara T, Kanai Y, et al. Tumour multifocality and grade predict intravesical recurrence after nephroureterectomy in patients with upper urinary tract urothelial carcinoma without a history of bladder cancer. Jpn J Clin Oncol. 2015;45(5):488-93. 
28. Hirano D, Okada Y, Nagane Y, Satoh K, Mochida J, Yamanaka Y, et al. Intravesical recurrence after surgical management of urothelial carcinoma of the upper urinary tract. Urol Int. 2012;89(1):71-7.

29. Ishioka J, Saito K, Kijima T, Nakanishi Y, Yoshida S, Yokoyama M, et al. Risk stratification for bladder recurrence of upper urinary tract urothelial carcinoma after radical nephroureterectomy. BJU Int. 2015;115(5):705-12.

30. Ito A, Shintaku I, Satoh M, Ioritani N, Tochigi T, Numata I, et al. Intravesical seeding of upper urinary tract urothelial carcinoma cells during nephroureterectomy: an exploratory analysis from the THPMG trial. Jpn J Clin Oncol. 2013;43(11):1139-44.

31. Kobayashi Y, Saika T, Miyaji Y, Saegusa M, Arata R, Akebi N, et al. Preoperative positive urine cytology is a risk factor for subsequent development of bladder cancer after nephroureterectomy in patients with upper urinary tract urothelial carcinoma. World J Urol. 2012;30(2):271-5.

32. Takaoka E, Hinotsu S, Joraku A, Oikawa T, Sekido N, Miyanaga N, et al. Pattern of intravesical recurrence after surgical treatment for urothelial cancer of the upper urinary tract: a single institutional retrospective long-term follow-up study. Int J Urol. 2010;17(7):623-8.

33. Shibuya T. HK, Shin T. MK, Sumino Y. SF, Mimata H. Preoperative positive urine cytology is a clinical independent risk factor for intravesical recurrence after laparoscopic radical nephrectomy in patients with upper tract urothelial carcinoma. Urology. 2014;(84):4 SUPPL. 1 (S253).

34. Jiang Y, Yao Z, Zhu X, Wu B, Bai S. Risk factors and oncological outcome for intravesical recurrence in organconfined upper urinary tract urothelial carcinoma patients after radical nephroureterectomy: A propensity scorematched case control study. Int J Surg. 2020;76:28-34.

35. Kim M, Kim JK, Lee J, Kim YS, Lee JL, Kwak C, et al. Adjuvant Treatments for Advanced Stage, Non-metastatic Upper Tract Urothelial Carcinoma: A Multicenter Study. Int J Radiat Oncol Biol Phys. 2019;104(4):819-27.

36. Zhang L, Wu B, Zha Z, Zhao H, Yuan J, Feng Y. The Prognostic Value of Lymphovascular Invasion in Patients With Upper Tract Urinary Carcinoma After Surgery: An Updated Systematic Review and Meta-Analysis. Front Oncol. 2020;10:487.

37. Guo RQ, Hong P, Xiong GY, Zhang L, Fang D, Li XS, et al. Impact of ureteroscopy before radical nephroureterectomy for upper tract urothelial carcinomas on oncological outcomes: a meta-analysis. BJU Int. 2018;121(2):184-93.

38. Leow JJ, Orsola A, Chang SL, Bellmunt J. A contemporary review of management and prognostic factors of upper tract urothelial carcinoma. Cancer Treat Rev. 2015;41(4):310-9.

39. Yoshida T, Kobayashi T, Kawaura T, Miyake M, Ito K, Okuno H, et al. Development and external validation of a preoperative nomogram for predicting pathological locally advanced disease of clinically localized upper urinary tract carcinoma. Cancer Med. 2020;9(11):3733-41.

40. Sung HH, Jeon HG, Han DH, Jeong BC, Seo SI, Lee HM, et al. Diagnostic Ureterorenoscopy Is Associated with Increased Intravesical Recurrence following Radical Nephroureterectomy in Upper Tract Urothelial Carcinoma. PLoS One. 2015;10(11):e0139976.

41. Tan P, Xie N, Ai J, Xu H, Xu H, Liu L, et al. The prognostic significance of Albumin-to-Alkaline Phosphatase Ratio in upper tract urothelial carcinoma. Sci Rep. 2018;8(1):12311.

42. Jones TD, Wang M, Eble JN, MacLennan GT, Lopez-Beltran A, Zhang S, et al. Molecular evidence supporting field effect in urothelial carcinogenesis. Clin Cancer Res. 2005;11(18):6512-9.

43. Hafner C, Knuechel R, Zanardo L, Dietmaier W, Blaszyk H, Cheville J, et al. Evidence for oligoclonality and tumor spread by intraluminal seeding in multifocal urothelial carcinomas of the upper and lower urinary tract. Oncogene. 2001;20(35):4910-5. 
44. Abrate A, Sessa F, Sebastianelli A, Preto M, Olivero A, Varca V, et al. Segmental resection of distal ureter with termino-terminal ureteric anastomosis vs bladder cuff removal and ureteric re-implantation for upper tract urothelial carcinoma: results of a multicentre study. BJU Int. 2019;124(1):116-23.

45. Sidransky D, Frost P, Von Eschenbach A, Oyasu R, Preisinger AC, Vogelstein B. Clonal origin of bladder cancer. $N$ Engl J Med. 1992;326(11):737-40.

46. Takahashi T, Kakehi Y, Mitsumori K, Akao T, Terachi T, Kato T, et al. Distinct microsatellite alterations in upper urinary tract tumors and subsequent bladder tumors. J Urol. 2001;165(2):672-7.

47. Heney NM, Daly J, Prout GR Jr, Nieh PT, Heaney JA, Trebeck NE. Biopsy of apparently normal urothelium in patients with bladder carcinoma. J Urol. 1978;120(5):559-60.

48. Takahashi T, Habuchi T, Kakehi Y, Mitsumori K, Akao T, Terachi T, et al. Clonal and chronological genetic analysis of multifocal cancers of the bladder and upper urinary tract. Cancer Res. 1998;58(24):5835-41.

49. Steiner G, Schoenberg MP, Linn JF, Mao L, Sidransky D. Detection of bladder cancer recurrence by microsatellite analysis of urine. Nat Med. 1997;3(6):621-4.

50. Jeon C, Kim M, Kwak C, Kim HH, Ku JH. Prognostic role of survivin in bladder cancer: a systematic review and meta-analysis. PLoS One. 2013;8(10):e76719.

51. Peng L, Zhou Y, Wang Y, Mou H, Zhao Q. Prognostic significance of COX-2 immunohistochemical expression in colorectal cancer: a meta-analysis of the literature. PLoS One. 2013;8(3):e58891.

52. Fan B, Zhang H, Jin H, Gai Y, Wang H, Zong H, et al. Is Overexpression of Ki-67 a Prognostic Biomarker of Upper Tract Urinary Carcinoma? A Retrospective Cohort Study and Meta-Analysis. Cell Physiol Biochem. 2016;40(6):1613-25.

53. Audenet F, Attalla K, Sfakianos JP. The evolution of bladder cancer genomics: What have we learned and how can we use it. Urol Oncol. 2018;36(7):313-20.

54. Dyrskjøt L, Reinert T, Algaba F, Christensen E, Nieboer D, Hermann GG, et al. Prognostic Impact of a 12-gene Progression Score in Non-muscle-invasive Bladder Cancer: A Prospective Multicentre Validation Study. Eur Urol. 2017;72(3):461-9.

55. Kim PH, Cha EK, Sfakianos JP, lyer G, Zabor EC, Scott SN, et al. Genomic predictors of survival in patients with high-grade urothelial carcinoma of the bladder. Eur Urol. 2015;67(2):198-201.

56. Azmi AS, Bao B, Sarkar FH. Exosomes in cancer development, metastasis, and drug resistance: a comprehensive review. Cancer Metastasis Rev. 2013;32(3-4):623-42.

57. Kara M, Yumrutas O, Ozcan O, Celik Ol, Bozgeyik E, Bozgeyik I, et al. Differential expressions of cancerassociated genes and their regulatory miRNAs in colorectal carcinoma. Gene. 2015;567(1):81-6.

58. Sjödahl G, Eriksson P, Liedberg F, Höglund M. Molecular classification of urothelial carcinoma: global mRNA classification versus tumour-cell phenotype classification. J Pathol. 2017;242(1):113-25.

\section{Figures}



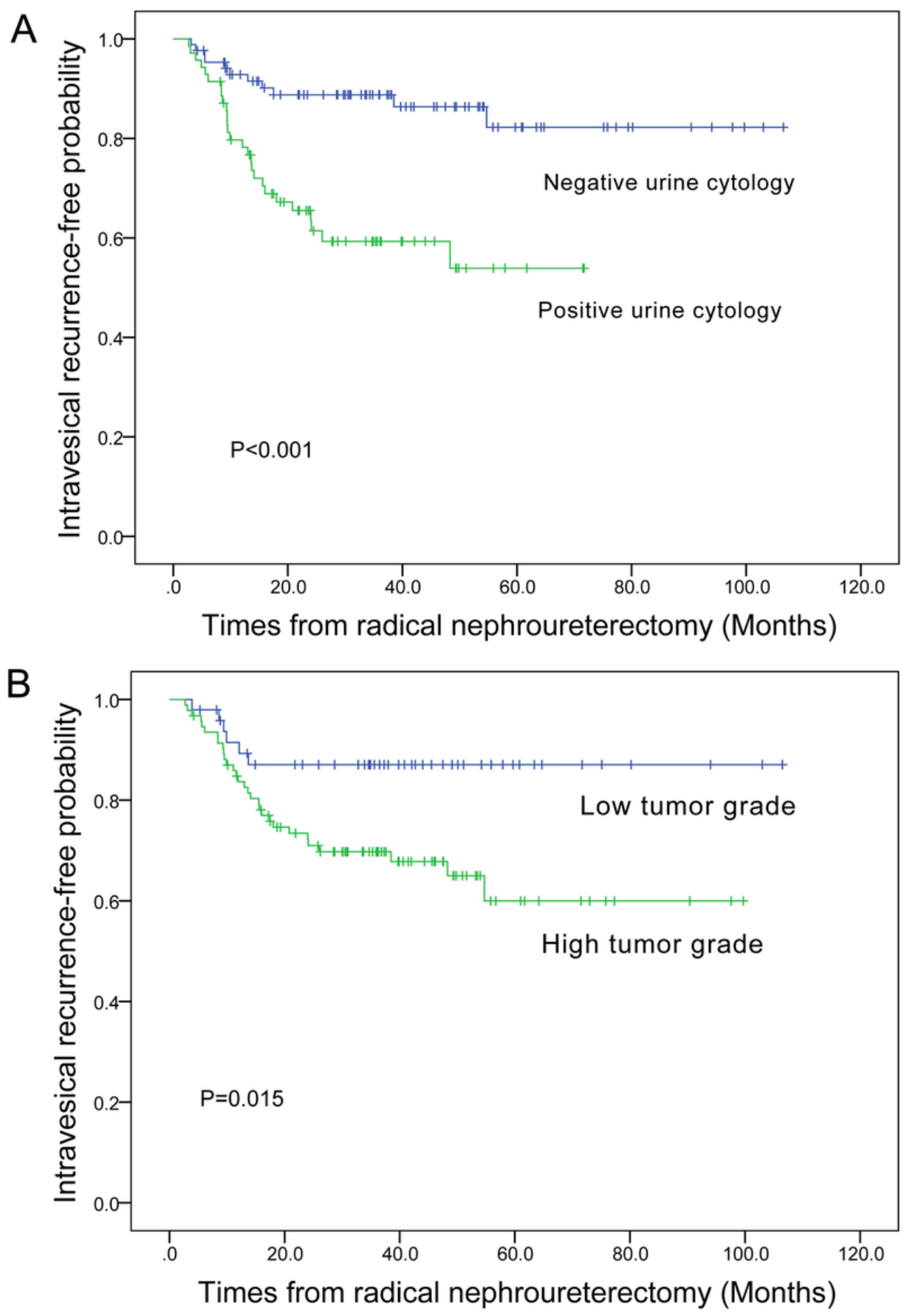

Figure 1

Kaplan-Meier curves for intravesical recurrence free survival of UUT-UC patients stratified by (A) the preoperative urine cytology (B) histological grade. Patients with preoperative negative urine cytology and low tumor grade demonstrated higher intravesical recurrence free survival rate $(P<0.001 ; P=0.015$, respectively, log rank test) 
Points

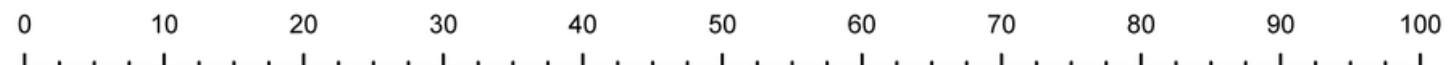

Age

$>=69$

Age

Gender

Tumor_side

Tumor_location

Tumor_focality

Histological_grade

$<69 \mathrm{~F}$

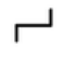

M Left

Therside

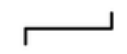

$\checkmark$

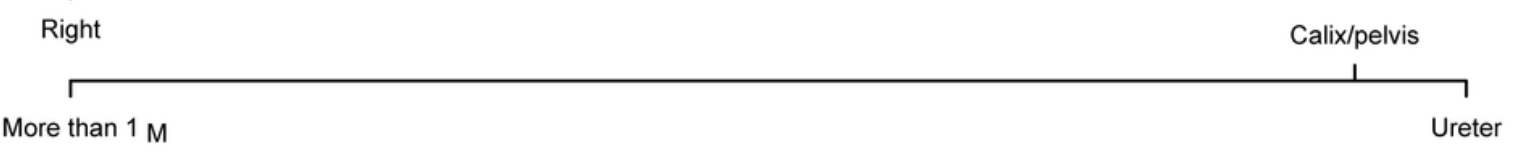

Pathologic_stage

Surgery_type
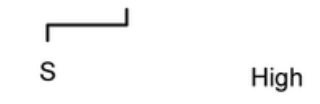

$$
\text { Low Tis-T1 }
$$

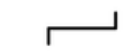

$$
\text { T2-T4 N1 }
$$

Preoperative_urine_cytology

Total Points

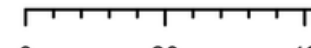

40

60

80

100

120

140

160

180

200

1-Year Recurrence-free Survival

3-Year Recurrence-free Survival

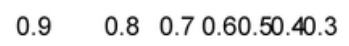

3-Year Recurrence-free Survival

5-Year Recurrence-free Survival

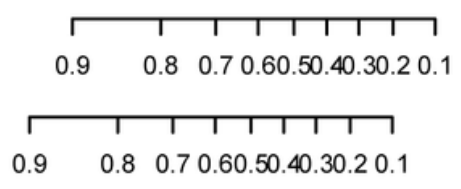

\section{Figure 2}

The nomogram for 1-, 3- and 5-years OS prediction of UT-UUC and its predictive performance. The independent prognostic factors (including age, gender, tumor side, tumor location, tumor focality, histological grade, pathologic stage, lymph node status, distant metastasis, and surgery type and preoperative urine cytology) were combined with the point designations to get total prognostic score 

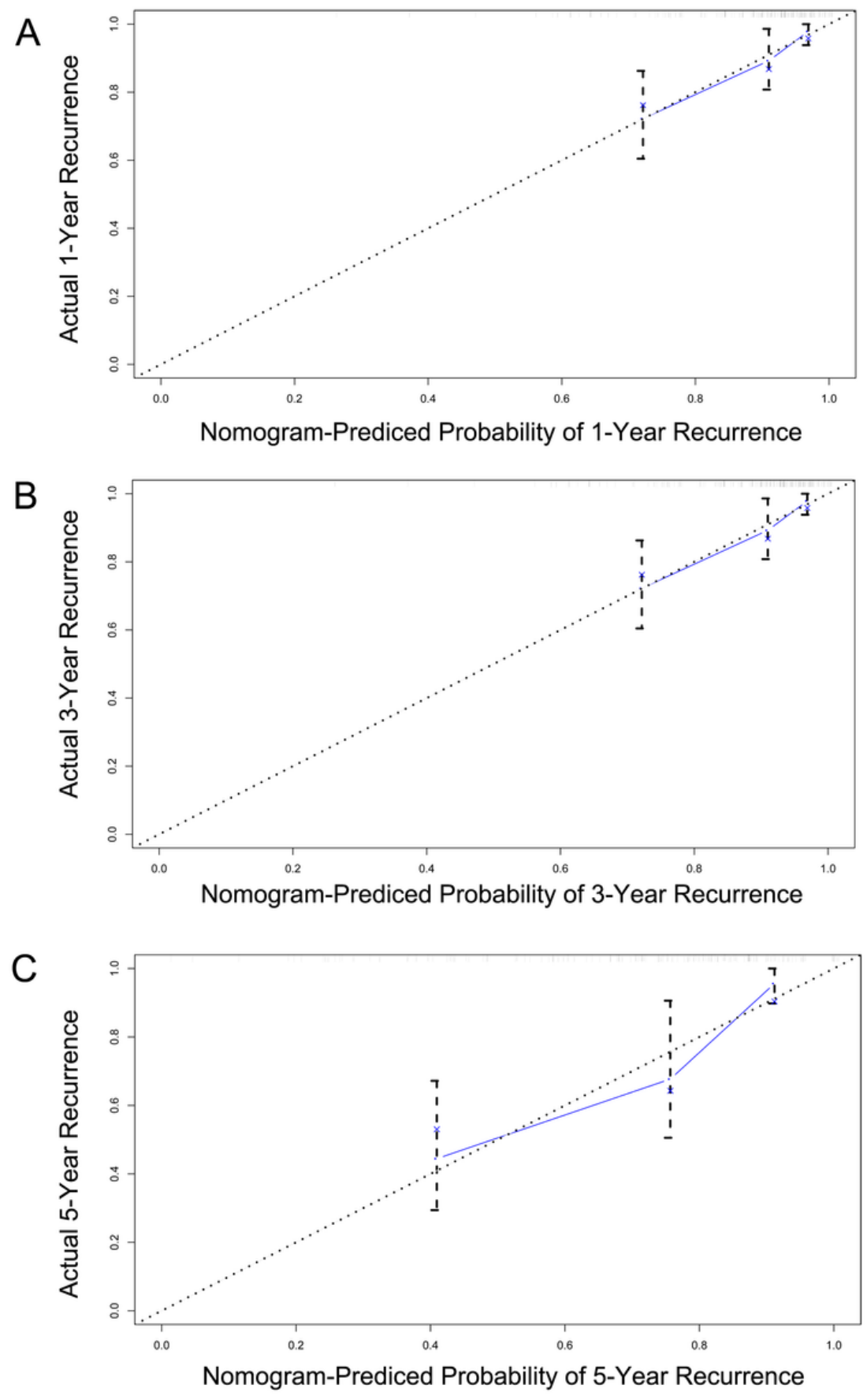

\section{Figure 3}

The calibration plots for the nomogram predictions of (A) 1-, (B) 3-,(C) 5-year OS. Nomogram-predicted probability is plotted on the x-axis; actual recurrence is plotted on the $y$-axis. The gray dotted line represented the ideal curve of calibration models. The blue broken line demonstrated the actual predictive accuracy; the bootstrap-corrected estimates was visually shown by blue X; vertical bars repersents the $95 \% \mathrm{Cls}$ 

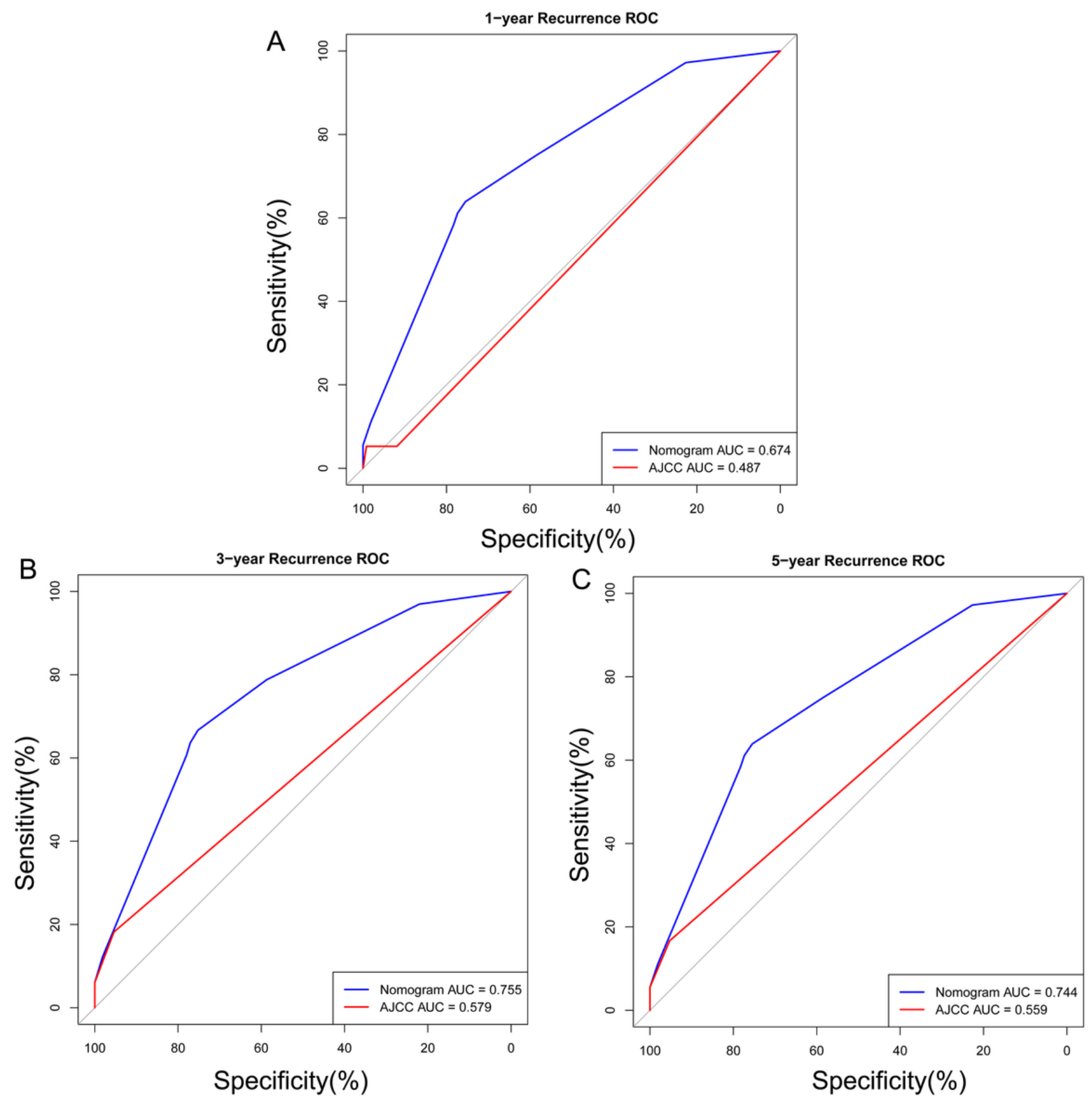

Figure 4

The ROC curves comparing the effectiveness of predicting OS between nomogram and AJCC score in (A) 1-, (B) 3-, (C) 5-year. Nomogram-predicted overall survival rates were indicated the blue lines; AJCC-predicted overall survival rates were indicated by the red lines 


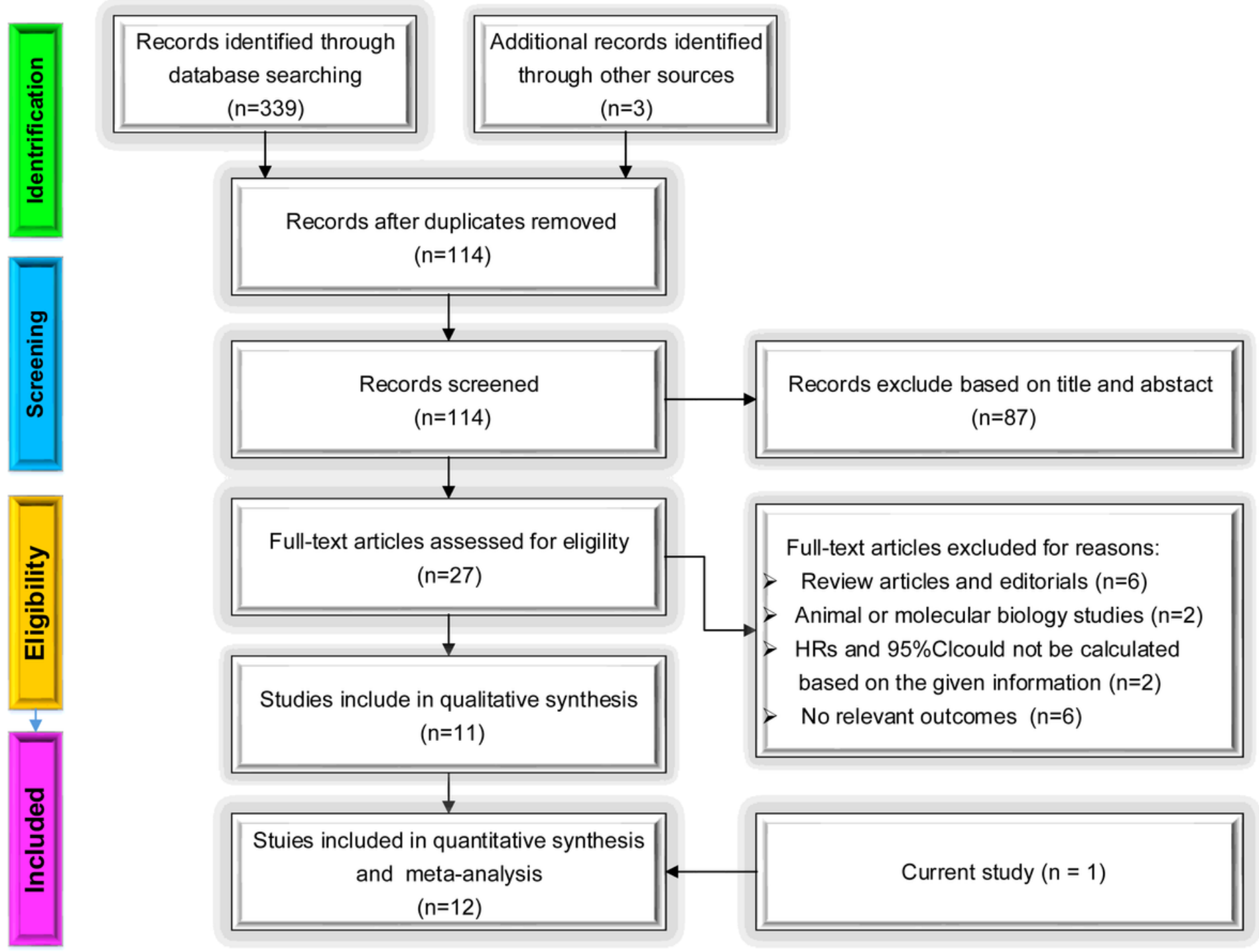

Figure 5

Methodologic flow diagram for selection of articles 
Study

ID

$\operatorname{HR}(95 \% \mathrm{Cl})$

Weight

Long X 2016 (1)

Long X 2016 (2)

Narukawa T 2015

Ishioka J 2015

Fang D 2014

Shibuya T 2014

Tanaka N 2013

Ito A 2013

Cho DS 2013

Hirano D 2012

Kobayashi Y 2012

Takaoka E 2010

This study

Overall (l-squared $=45.3 \%, p=0.038$ )

NOTE: Weights are from random effects analysis

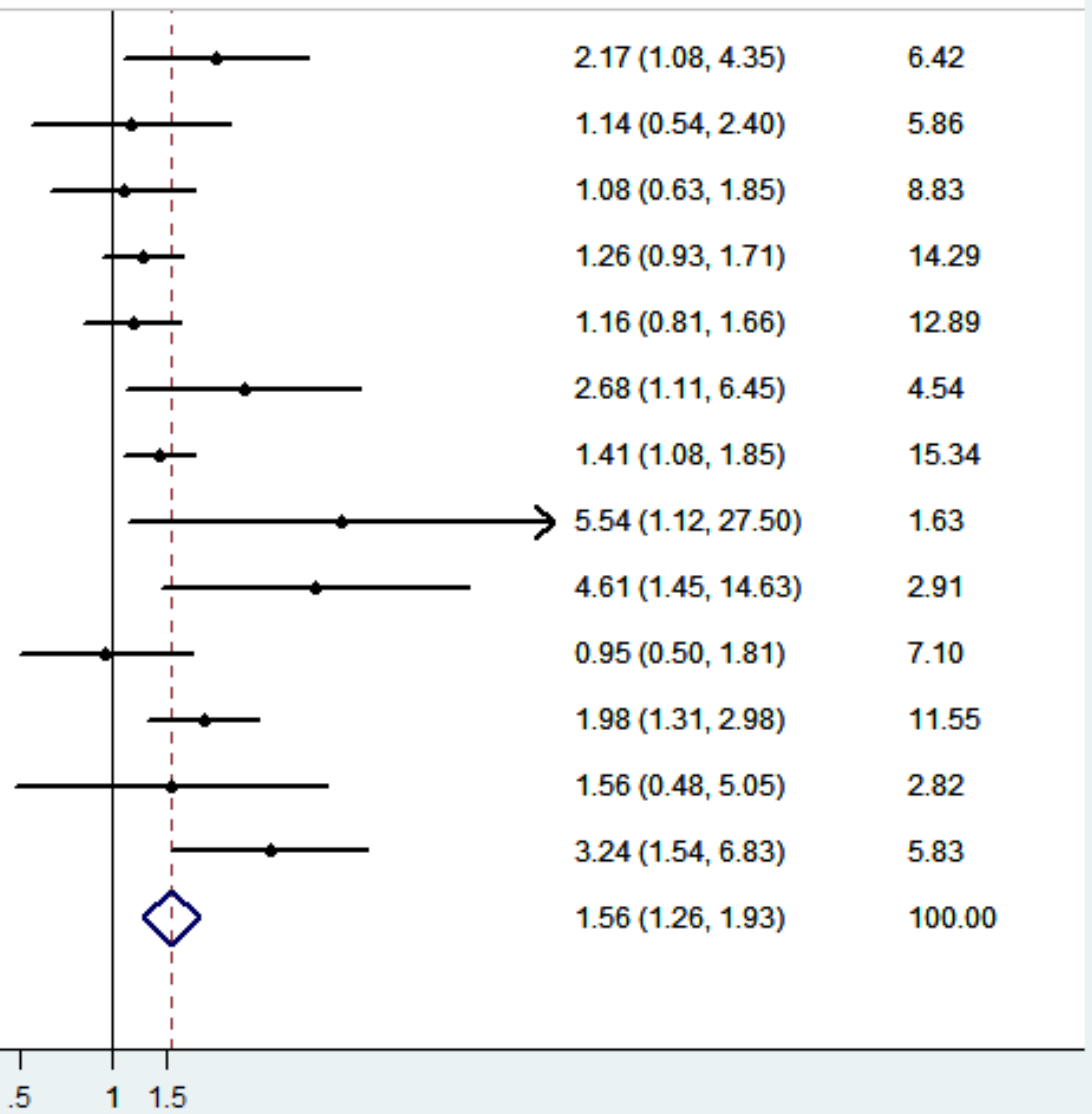

\section{Figure 6}

Forest plot showing the risk of intravesical recurrence in UUT-UC patients with preoperative positive urine cytology in total analysis. Squares in each trial are on behalf of hazard ratios; $95 \%$ confidence interval(Cl) was represented by the horizontal line which traverse the square. the estimated combined effect was represented by the diamonds. According to heterogeneity analysis, the Mantel-Haenszel random-effect model was selected 
A

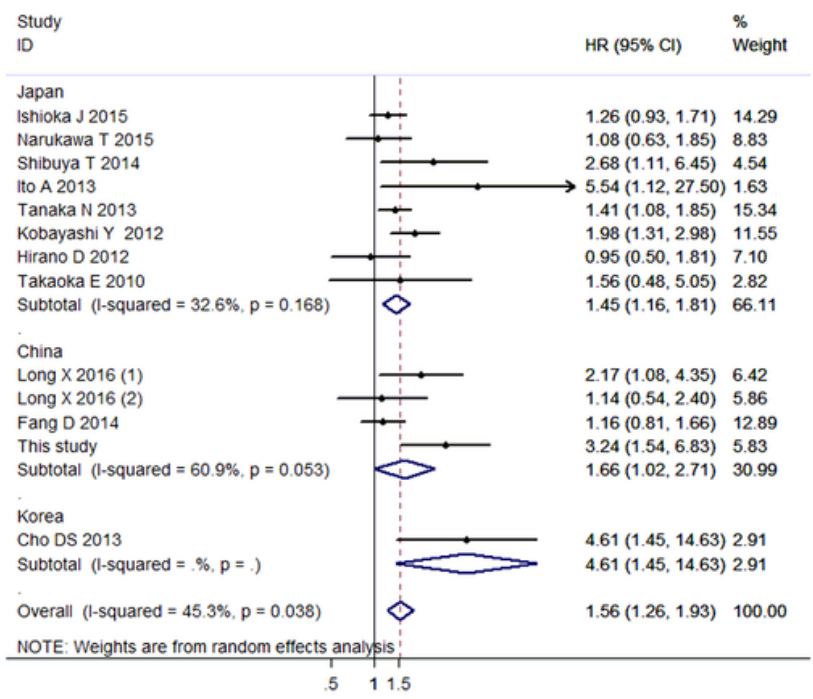

C

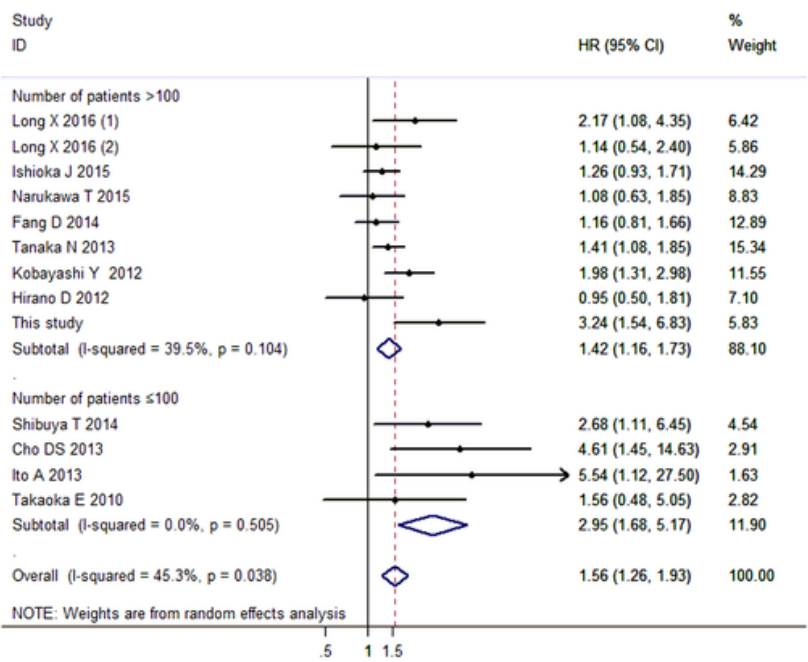

B

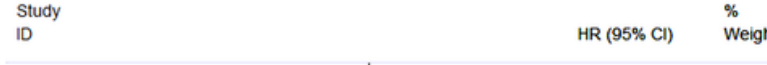

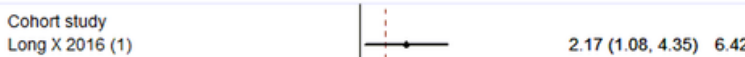
$\begin{array}{lll}\text { Long X } 2016(1) & 2.17(1.08,4.35) & 6.42 \\ \text { Long } X 2016(2) & 1.14(0.54,2.40) & 5.86\end{array}$ shioka J $2015 \quad 1.26(0.93,1.71) \quad 14.29$ $\begin{array}{llll}\text { Fang D } 2014 & 1.16(0.81,1.66) & 12.89\end{array}$ Shibuya T $2014 \quad \longrightarrow \longrightarrow 2.68(1.11,6.45) \quad 4.54$ Tanaka N $2013 \rightarrow \rightarrow 1.41(1.08,1.85) \quad 15.34$ Hirano D $2012 \quad \longrightarrow \quad 0.95(0.50,1.81) 7.10$ This study $3.24(1.54,6.83) 5.83$ Subtotal (I-squared $=40.2 \%, p=0.111) \quad \diamond \quad 1.44(1.15,1.80) 72.26$

Case control study Narukawa T 2015 Cho DS 2013

Kobayashi Y 2012 Takaoka E 2010 $\begin{array}{lll}1.98(1.31,2.98) & 11.55\end{array}$ \begin{tabular}{llll} 
& \\
\hline & $1.77(1.06,2.93)$ & 26.11
\end{tabular}

Randomized Controlled Tria

Ito $A 2013$
Subtotal (l-squared $=\%, \mathrm{p}=$.) $5.54(1.12,27.50) 1.63$

Overall (I-squared $=45.3 \%, p=0.038) \quad \diamond \quad 1.56(1.26,1.93) \quad 100.00$ NOTE: Weights are from random effects analysis

$\begin{array}{lll}5 & 1 & 1.5\end{array}$

D

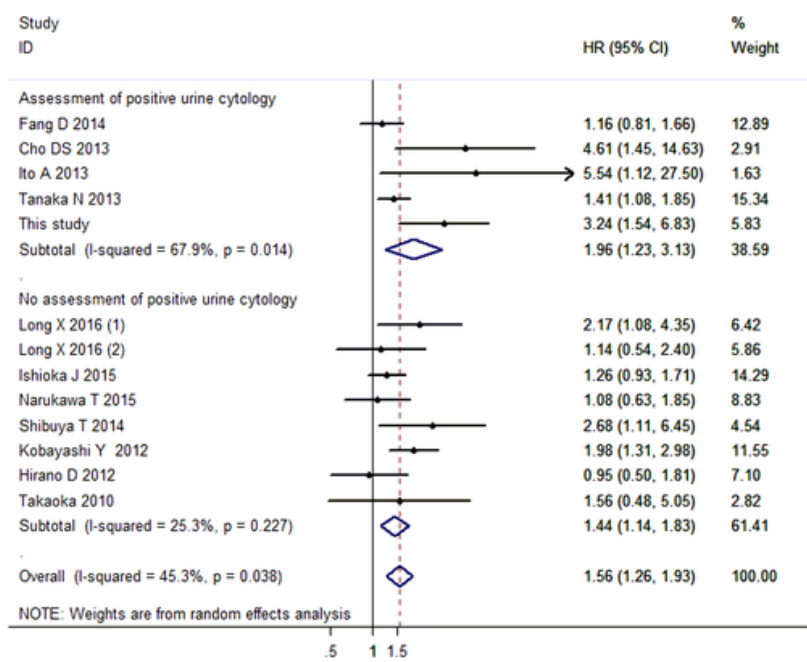

\section{Figure 7}

Forest plot showing the risk of intravesical recurrence in UUT-UC patients with preoperative positive urine cytology by subgroup analysis of (A) region (B) study types (C) sample size (D) assessment of urine cytology. Squares in each trial are on behalf of hazard ratios; $95 \%$ confidence interval(CI) was represented by the horizontal line which traverse the square. the estimated combined effect was represented by the diamonds. According to heterogeneity analysis, the Mantel-Haenszel random-effect model was selected 


\section{Begg's funnel plot with pseudo $95 \%$ confidence limits}

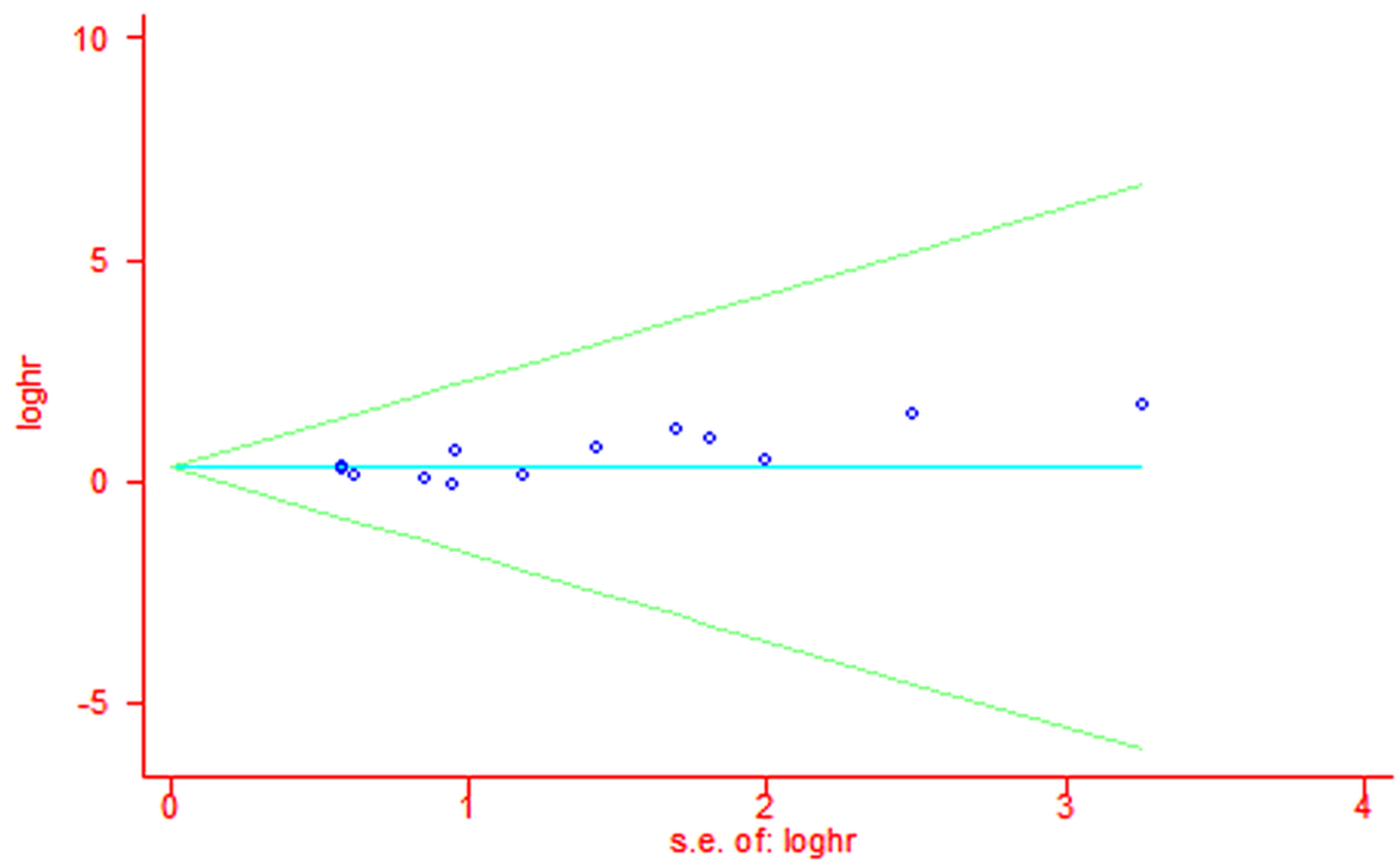

\section{Figure 8}

Funnel plot for risk of intravesical recurrence in UUT-UC patients with preoperative positive urine cytology 